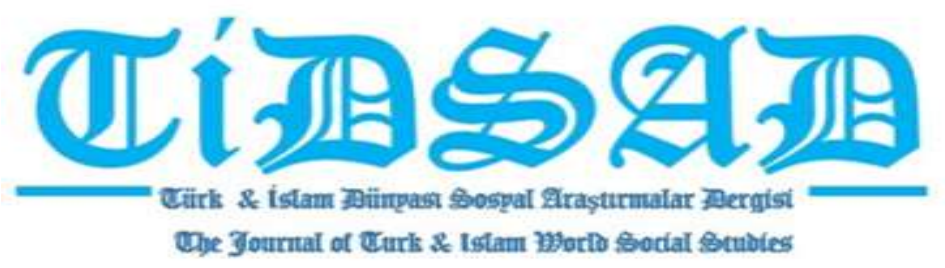

Yıl: 6, Sayı: 23, Aralık 2019, s. 8-16

Doç.Dr Mikail TEL

Fırat Üniversitesi, Spor Bilimleri Fakültesi, Elazı $\breve{g}$, mtel@firat.edu.tr

\title{
TAEKWONDO VE FAİR PLAY
}

\section{Özet}

Taekwondo ferdi ve mücadele sporları içerisinde gösterilen, uzakdoğu kökenli ve olimpik bir spor branşıdır. 3 bin yıllık bir mazisi olmasına rağmen 2000 yılında olimpik bir spor haline gelmiştir. Dünyada 140 ülkede 7 den 70 yaşlarına kadar 40 milyon insandan daha fazla insan bu sporu yapmaktadır.

$\mathrm{Bu}$ araştırmada taekwondo sporu ve fair play kavramı ele alınarak taekwondo sporu içerisinde sistematik olarak yapılan bazı ritüellerin fair play açısından değerlendirilmesi yapılmıştır.

Çalışmada, taekwondo sporu ile ilgili yazılan kitaplar incelenmiş ve taekwondo müsabakaları izlenerek gerekli değerlendirmeler not edilerek yorumlanmıştır. Araştırmada belgesel tarama yöntemi kullanılmıştır. Belgesel tarama şu aşamalardan oluşmakta: istenen amaca yönelik olarak kaynakları bulma, okuma, not alma ve değerlendirme işlemlerini kapsamaktadır.

Taekwondo isminin içerisinde fair play kavramı geçmektedir. Do kavramı; yol, ahlak, etik olarak ifade edilmektedir. Taekwondo müsabakalarında sporcuların müsabakaya başlamadan önce hakemleri, seyircileri selamlaması ve rakibi ile el sıkışıp birbirine başarılar dilemesi fair playa verilecek örneklerden bazılarıdır. Taekwondo müsabakası içerisinde yere düşen rakibe vurulmasının yasak olması ve cezai müeyyidesinin olması da dikkat çekmektedir.

Yine taekwondo salonlarında ve antrenmanlarda bayrağa selam, hocaya selam ve taekwondo yemini de ayrıca fair play açısından önemlidir. Antrenmanlarda sporcular arasındaki kuşak derecesi spordaki hiyerarşik yapı açısından da önemlidir. Taekwondo kitap ve salonlarında "taekwondo barış içinde yarıştır", “taekweondo' cu her şeyi kırar ama bir kalbi asla” gibi veciz ifadeler bu spor branşının fair play açısından mükemmel bir spor branşı olduğunun bir göstergesidir. 
Anahtar Kelimeler: Taekwondo, Fair Play, Fair Play ve Taekwondo

\title{
TAEKWONDO AND FAIR PLAY
}

\begin{abstract}
Taekwondo is a far east-originated Olympic sports branch, which is viewed among individual and combative sport. Although it has a history extending to 3 thousand years, it has become an Olympic sport in 2000. In the world, more than 40 million people in 140 countries, aging from 7 to 70 , practice this sport.

In this study, taekwondo sport and the concept of fair play will be investigated and the evaluation of several rituals conducted in taekwondo sport will be evaluated in terms of fair play.

In the study, the books written about taekwondo sport were investigated and the necessary evaluations were interpreted by watching taekwondo competitions and taking notes. In the study, the documental survey was adopted. The documental survey method consists of the following steps: finding the resources for the desired aim, reading them, taking notes about them and the evaluation process.

The definition of taekwondo includes the concept of fair play. The term, Do, is referred to as the ways, morals and ethics. In taekwondo competitions, athletes first salute the referees and the audience, shake hands with their opponents and wish luck, which covers some of the examples of fair play. The fact that it is not allowed to attack a fallen opponent in the competition and it has penal sanctions also attracts attention.

Furthermore, in taekwondo centers and training, saluting the flag and the coach and taking the taekwondo oath are of importance in terms of fair play. In training, the ranks of belts among the athletes have importance in terms of the hierarchical structure in sports. Concise statements such as "Taekwondo is a race in peace.", and "Taekwondo athletes break everything but a heart." indicate that this branch of sports is a perfect sports branch in terms of fair play.
\end{abstract}

Keywords: Taekwondo, Fair Play, Fair Play and Taekwondo

\section{GíRIŞ}

Spor, insan hayatının tüm dönemlerinde önemli bir yer tutmaktadır. Bireyler sportif aktiviteleri farklı amaçlarla yapar. Bu amaçlar; fiziksel sağlığı artırmak, serbest zaman faaliyetini dolu bir şekilde geçirmek ve meslek sahibi olmak şeklinde sınıflandırılmaktadır. Bu amaçlarına ulaşmak isteyen isteyen bireyler, kendi özelliklerine uygun ve sevdikleri bir spor branşını yaparlar. Bu branşlardan biride Taekwondo sporudur (Şahin, 2002). Taekwondo, ferdi ve mücadele sporları içerisinde olan, uzakdoğu kökenli ve olimpik bir spor branşıdır (Tel, 2006; Türkmen, 2004). Taekwondo el ve ayakların sistemli bir şekilde kullanılarak, saldırılara karşı koruma ve savunma yapılan Kore döğüş sanatıdır (Hausmann, 1998; Tel ve Ark., 2004). Taekwondo Hem vücut hem de ruh ve zihnin gelişimini sağlayan bir spor branşıdır. Uzak doğuya has ferdi ve mücadele sporları içerisinde gösterilen bir spor dalı olan Taekwondo ülkemizde son y1llarda yoğun ilgi görmektedir ( Özsoy ve ark. 2018). 
Taekwondo, el ve ayakların belirli bölgeleri ile yapılan savunma ve vuruş tekniklerinden oluşan ayrıca sporcuda ahlaki değerlerin yücelmesinde katkıda bulunan bir spor dalı olarak da tanımlanabilir (Tel, 2006). Taekwondo sporunun amacı, bir tahtayı, bir tuğlayı kırmak veya bir yumruk ve ayakla düşmanı öldürmek ve mükemmel bir savunma sanatını öğrenmek değildir. Taekwondo'nun amacı, bir spor dalı olarak dövüş ve savunma sanatlarının eğitimini almak, ruh halimizi iyi yönde yetiştirmek ve fiziksel olarak sağlıklı ve bedeni disiplin altına almaktır (Yalçınkaya, 1986). Taekwondo her ne kadar sert ve tehlikeli bir spor olarak algılanmış ise de bilimsel gelişmeler Taekwondo' yu her yaşta insanların güvenle yapabileceği bir spor haline dönüştürmüştür (Toh, 1980). Taekwondo tahrip edici ve şiddet içeren bir spor değildir, aksine hareketleriyle tamamen estetik ve sportiftir. Taekwondo müsabakaları incelendiğinde sporcuların rakibini yaralamak için müsabaka yapmadığını, spor branşının kuralları doğrultusunda fiziksel ve zihinsel yollarla kendine özgü teknikleri uygulayarak puan almak için yapıldığı görülmektedir (Tel, 2004).

Taekwondo bir savunma sanatıdır. Bu sporun en önemli unsuru üstün seviyede kendilerini koruyabilmesi değil, bu sporu yapan kişilerde kendine güven duygusunu geliştiren bir spor olmasıdır. Kendine güven duygusu, insanları zayıf olanlara karşı davranışlarında hoşgörü sahibi ve cömert kılar. Eşit koşullarda bir rakiple karşılaştıklarında içinde yetişmiş oldukları ruh onların güçlerini gereksiz yere ve özellikle insafsız bir anlayışla sarf etmelerini önler (Ghorbanzadehkoshki, 2009). Ülkemizde Taekwondo spor dalının lisanslı sporcu sayısına (210.617) ve faal sporcu sayısına (9.237) (www.gsgm.gov.tr/istatistik/sporcusayilari) bakıldığında, bu sporu Türk insanının sevdiği bir spor dalı haline geldiğini görmek mümkündür. Pehlivan (1992) tarafindan üniversite öğrencilerine yapılan araştırmada ülkemizde Uzakdoğu sporlarına özellikle gençlerin ilginin olduğunu çalışmasında belirtmiştir. Taekwondo bugün Türkiye'de en fazla özel spor okulu ve spor kulübü olan bir spor dalı görünümündedir (Tel ve ark. 2001). Araştırmalarda, özellikle gençler tarafından sevilerek yapılan bu spor branşının popülaritesi nereden kaynaklandığına bakıldığında ve "Niçin Taekwondo sporunu yapıyorsunuz?" sorusuna verilen cevaplarda, taekwondonun içeriği, özü ve sportif değerini anlamak mümkündür. Verilen cevaplarda en yüksek oranları; sağlığı koruma ve fiziksel kuvveti arttırmak, self defans (hücum ve savunma) tekniklerini öğrenmek, kendine güven ve sabırlı olmak duygusunu geliştirmek, iyi bir sporcu olmak, taekwondo antrenörü olmak ve ekonomik gelir elde etmek, yaşama huzur katmak ve aktif hayat tarzını korumak, savaş sanatlarının gizemi ve doğu kültürünü öğrenmek, farklı ve estetik görünmesi gibi sebepleri olduğunu belirtmişlerdir (Kım, 2006 \& Tel ve ark. 2001).

\section{Fair Play Kavramı}

Fair play kavramı bir Anglosakson sözcüğü olarak tüm dünyaya yayılmış evrensel bir Ülkemizde fair play kavramının karşıllğı ' sportmenlik' veya 'sportmence' kelimeleri kullanılıyordu (Donuk ve Şenduran, 2006). Türkçe bir sözcük olan "yoğurt” dünyada kullanılır hale gelmişse, televizyon ve radyo gibi fair play sözcüğü ortak ve evrensel bir sözcük haline dönüşmüştür. Fair play, spor müsabakalarında bireylerin kendi egoizmlerini bir tarafa bırakarak, özveride bulunarak doğru ve dürüstlükten taraf olma becerisidir(Arıpınar- Donuk, 2011). 
'Fair play sporda centilmenlik olayıdır'.

Fair play centilmenliktir.

Fair play dürüst oyun ve dürüst davranıştır.

Fair play etik bir davranıştır.

Fair play sporda sevgi, dostluk ve kardeşlik anlayışıdır.

Fair play 'tanrının sesini duymak' (vicdanın sesini dinlemek) tir.

Fair play rakibe, hakeme, seyirciye, basına, antrenöre ve takım arkadaşlarına saygıdır.

Fair play hakça mücadele etmektir

Fair play kurallara göre oynamak- yarışmaktır.

Fair play sportmence davranmaktır.

Fair play hoşgörü ve saygıdır.

Fair play spor kültüründe sporculardan beklenen davranışlardır.

Fair play sporda rakibi bir düşman değil, oyunun bir parçası olarak görmektir.

Fair play rakibe saygı, ona fizyolojik ve psikolojik açıdan zarar vermemedir.

Fair play yarışmalarda hile ve şiddete yönelmemektir.

Fair play komisyonuna göre; Adil rekabet, saygı, arkadaşlık, takım ruhu, eşitlik, dopingsiz spor, dürüstlük, dayanışma, hoşgörü, özen, mükemmellik ve neşe gibi yazılı ve yazılı olmayan kurallara saygidır (CiFP, 2019).

Fair play, bireyin onuruna gösterilen saygının belirtisi olarak doğmuş ve sporun tüm aşamaları ile tüm kademelerinde doğru, dürüst ve adil oyun oynamayı ereksel bir ahlak ülküsü şeklinde kendini benimsetmiştir(Pehlivan, 2004).

Yıldıran (2002), fair play kavramını; müsabaka ve yarışma sırasında sporcunun, güç durumlarda kurallara sabırlı, tutarlı aynı zamanda bilinçli biçimde uymaları, firsat eşitliğini korumak için haksız avantaj ve yolları kabul etmemeleri, rakibin haksız dezavantajlarını kullanıp faydalanmamak, rakibine düşman gibi davranmamak, bunun aksine oyunun oluşmasını sağlayan eşit hakka sahip bir partner biçimde görmek olarak tanımlamaktadır

Donuk ve Arıkan (2011) fair play' bakış açısını daha geniş kapsamda ele almıştır. Fair play'in yalnızda sporcuların uymak zorunda olduğu davranışlar şeklinde görülmemesi gerektiğini, bunun yanı sıra, yönetici, antrenör, hakem, taraftar, basın mensubu hem maç öncesi hem de maçtan sonra fair play ruhuna uyan davranışları sergilemesi gerektiğini ifade etmişlerdir.

Fair play alakalı bir takım kurallar bulunmakta olup, bu kurallar şu biçimdedir:

- Oyunun kurallarına riayet edilmesi,

- Şans eşitliğini korumak,

- Kazanan tarafi tebrik etme,

- Rakibini oyunun bir parçası şeklinde görme, 
- Oyunun neticesini kabullenme ve saygı duyma,

- Oyunda hile veya şiddete yönelmemek

Fair play; Uluslararası Fair Play Komisyonu açısından bir takım temel değer ilkelerine sahiptir:

Adil Rekabet: Sporda başarının adil ve dürüst yollarla ve eşit durumlarda yarışılarak elde edilmelidir.

Sevgi-Saygı: Sporun toplumda kolektif bir biçimde yaşayan kişilerin bir araya gelerek bir etkinlik yapmasına imkân sağlar. Farklı düşüncelere sahip kişilerin bu düşüncelere saygı duyması, hoşgörülü olması, paylaşımcı bir yapıya sahip olmaları spor neticesinde büyük ölçüde imkân sağlamaktadır.

Dostluk ve Hoşgörü: Rekabet veya mücadele dostluğu engelleyemez. Girilen mücadeleler rekabeti ve dostluğu engellemediği gibi bunun aksine, dostluklar asil rekabetler ile beraber büyüyebilir.

Sorumluluk: Kişinin katılmış olduğu müsabaka ve yarışmalarla birlikte sosyal açıdan ilişkileri de güçlenmektedir. Bunun neticesinde sorumluluk bilince ulaşmayı kolaylaştırmaktadır. Burada haz duyarak aynı zamanda aidiyet duygusunu geliştirerek sahip olduğu sorumluluk bilincini hayatının diğer yönlerine de yansıtarak anlamlı bir davranış değişikliği yapmış olduğu söylenebilir (Şahan, 2008). Spor ayrıca yardım ve iş birliği çerçevesinde bir düzen sağlama etkinliğini sağlarken anlayış ve sorumluluk duygusunu geliştirir (Erkal ve ark., 1998).

Eşitlik: Sporda eşit biçimde rekabet etmek önem teşkil eder. Aksi durumlarda performans doğru bir biçimde belirlenemez (Yıldız, 2016). Başarı ve kazanma hırsı içindeki birçok sporcu ve kulüp kazanma adına etik ve ahlaki değerlere uymayan davranışlara yönelebilir. Doping kullanımı ve teşvik pirimi verme sporun eşit ilkesine büyük zarar vermektedir.

Dopingsiz Spor: Adil ve dürüst oyun, uyuşturucu veya doping alarak bazı hileli yollara başvurmamak anlamına gelmektedir. Sporcunun performansını arttırmak için kullanılan ilaç ve yöntemler haksız ve eşit olmayan rekabete neden olmaktadır.

Bütünlük: Adil bir oyun için dürüst olmanın yanı sıra ahlaki değerlere sahip olmak esastır. Gerçek bir şampiyon olmayı hedefliyorsanız sporu sağlıklı etik bir çerçevede yapılması önem teşkil eder.

Dayanışma: Birbirinizi destekleme, duygu, hedef ve hayallerinizi paylaşmak son derece önemlidir. Karşılıklı olarak birbirinizi desteklemek sahada başarıyı elde etmeyi sağlar.

Mükemmellik: Yapılan bütün spor dalları kişilerin sağlıklı bir biçimde hayatlarını sürdürebilmesi için gereklidir. İnsanlar, sporla beraber mükemmelliği devam ettirmek için çaba harcarlar.

Sevinç: Modern Olimpiyat Oyunları'nın babası olarak bilinen Pierre de Coubertin, "Hayattaki en önemli şey zafer değil, mücadeledir. Önemli olan kazanmış olmak değil, iyi mücadele etmek" ifade etmiştir. Müsabakalar ve yarışmalar da rekabet yoğun bir biçimde yaşansa dahi önemli olanın sonuca sevinme, kaybeden taraf için niçin yenildiği, başarmak için daha neler yapmalıyımın yanı sıra sürekli çalışmalıyım düşüncesiyle hareket etmelidir. 
Fair play kavramı, kişilerin toplumlara uyum sağlamalarını ve ekip ruhunu oluşturmasını sağlar. Spor; milliyetlerin, politikaların, dinlerin ve aynı zamanda kültürlerin çoğunlukla bölündüğü yerlerde fair play ruhu çerçevesinde birleşmesini sağlayabilir. Fair playin özünde işbirliği vardır ve bu sayede bütün toplum katmanları bir araya gelip güzel davranışlar sergileyebilir.

Fair play ruhunu tüm spor branşlarına yaymak için uluslararası olimpiyat komitesine bağlı olarak kurulan Uluslararası Fair Play Komitesi, faaliyetlerine tüm dünyada devam etmektedir. Fair play ruhunu yaymak için ülkelerdeki milli olimpiyat komitelerine bağlı olarak çalışan fair play komitesi tüm ülkede olimpizm ve fair playi yaygınlaştırmak için belirlediği hedeflere yönelik faaliyetler yapmaktadırlar (Hergüner ve Tel, 2019)

\section{Materyal ve Metot}

$\mathrm{Bu}$ araştırmada, taekwondo sporunun fair play prensiplerine ne ölçüde yakın olduğu teorik bir kapsam içerisinde incelenmeye çalışılmıştır. Konu ile ilgili yazılan kitaplar, dergiler incelenmiş ve Taekwondo müsabakaları izlenerek gerekli değerlendirmeler not edilerek yorumlanmıştır. Araştırmada belgesel tarama yöntemi kullanılmıştır (Karasar, 2006 \& Yıldırım ve Şimşek, 2005). Belgesel tarama şu aşamalardan oluşmakta: istenen amaca yönelik olarak kaynakları bulma, okuma, not alma ve değerlendirme işlemlerini kapsar.

\section{Taekwondo sporundaki ve Müsabakalarındaki fair play olarak değerlendirilecek noktalar:}

\section{1- Taekwondo İsmi ve Fair Play:}

Taekwondo sporuna bakıldığında, tae: ayak ; kwon: el ; do: ahlak, disiplin, sayg, izlenecek yol anlamlarına gelmektedir. Yani bu spor branşının içerisinde fair play kelimesi olarak ifade edilebilecek olan 'do' kelimesi geçmektedir. Do prensibi nedir diye sorulduğunda ise; ahlak ve fazilete ulaşmak için takip edilmesi gereken yol olarak ifade edilmektedir.

\section{2- Taekwondo'nun Prensipleri}

Taekwondo eğitimleri sırasında spor merkezleri ve kulüplerinde verilen bu prensipler fair play açısından önem arz etmektedir. Bu prensipler: Rakibine ve arkadaşlarına karşı nazik ol, Alçakgönüllülük, Saygı, Sabır, Birlik, Dinç kalmak olarak sıralanmaktadır (Kim, 1975).

\section{3- Müsabakalarda Fair Play Örnekleri:}

a) Müsabakaya çıkarken önce kendi antrenörüne selam: Taekwondo müsabakalarında Fair play açısından anlamlı olan hareketlerden biride sporcunun maça çıkmadan önce hocasına saygı olarak selam vererek müsabaka alanına girmesi görülmüştür.

b) Müsabaka yapacağı sporcuya selam ve başarı dileme: Bu davranışta Fair play açısından önemlidir. Az sonra kıyası mücadele edeceği rakibi ile selamlaşıp tokalaşması önemli görülmüştür.

c) Hakeme selam: sporcular müsabakayı yönetecek olan hakeme de saygı ifadesi olarak gösterilecek olan selamı başları ile hafifçe eğilerek verirler. Bu hareket de fair play açısından önemlidir.

d) Seyirciye selam verilir: müsabakayı izlemeye gelen spor severlere de saygisına selam vererek ifade ederler. Başı öne hafifçe eğerek seyirciye doğru dönerek selamlarını ve saygılarını sunarlar. 
e) Müsabaka sonrası tebrik etme. Müsabaka sonrası kazanan sporcu ilan edilince rakipler birbirini tebrik ederek sahadan ayrılırlar. Aynı seremoni hakem seyirci içinde yine yapılmaktadır. Hatta bazı sporcular rakip antrenörlere de selam vererek başarı dileklerinde bulunmaktadırlar. Buda başarılı olanı tebrik etmek fair play prensipleri içerisinde bulunmaktadır.

\section{4- Müsabaka İçerisinde Uygulanan Bazı Kurallarda Fair Play Örnekleri:}

Taekwondo antrenmanlarında müsabaka kuralları öğrencilere anlatılmaktadır. Bu müsabaka kurallarına uymayanlara 0.5 ihtar veya -1 ceza puanı verilmektedir. Bunlar: Yere düşen rakibe vurulmaz, elle yüze vurmak yasak, rakibin sırtına vurulmaz, hassas ve tehlikeli bölgelere vurmak, çelme takmak, itmek, firlatmak, tutmak, küfür etmek yasaktır, kural ihlalidir ceza olarak değerlendirilmektedir. Yine müsabaka içerisinde herhangi bir aksi durumda sporcu hakeme dönerek müsabakayı maçı durdurabilir.

\section{5- Taekwondo Yemini}

Taekwondo antrenman salonlarında asılı olan Taekwondo yemini fair play açısından önemli görülmektedir.

'Bizler Atatürk yolunda müş̧erek gayede birleşmiş bulunuyoruz.

Bizler ruh ve vücutlarımızı Do prensiplerine uygun olarak eğitiyoruz.

Bizler yönetmeliklere ve kurallara uyacak ve bağlı bulunduğumuz spor teşkilatına ve hocalarımıza itaat edeceğiz' şeklinde yazılmaktadır.

\section{6- Taekwondo Salonlarında Fair Play Uygulamaları:}

Taekwondo spor merkezlerinde uygulanan belli kurallar vardır. Ve antrenmanlar belli bir düzen (sıra) içerisinde yapılmaktadır. Salonda antrenman başlamadan önce bayrağa selam ve hocaya selamla antrenmanlar başlar. Sporcular karşılıklı uygulayacağ her hareketin başında birbirine selam vererek tekniğe başlarlar. Taekwondo sporunda uygulanan kuşak sırası vardır. Bu sıralama spor bilgi ve seviyesini göstermektedir. Kuşak sırasına göre bir hiyerarşik yap1 mevcuttur ve üst kuşaklar ön sıralarda yer alır.

Taekwondo salonlarında bulunan veciz bazı sözler de fair play açısından önemli görülmüştür.

'Taekwondocu her şeyi kırar ama bir kalbi asla'

'Taekwondo nezaketle başlar, nezaketle biter'

'Taekwondo barış içinde yarıştır'

Ben sporcunun zeki, çevik ve ahlaklısını severim' Mustafa Kemal Atatürk ' ün bu sözü bütün Taekwondo merkezlerinde yazılı olduğu görülmüştür.

\section{Genel Değerlendirme ve Sonuç}

Yapılan bu araştırmada Taekwondo sporunun fair play ruhuna ve prensiplerine uygun bir spor branş1 olduğu belirlenmiştir. Taekwondo tüm spor branşları gibi belirli kurallar dahilinde yapılmakla beraber isminde fair play ruhu görülmektedir. Taekwondo müsabaka öncesi, anında ve müsabaka sonrası fair play ruhunun hakim olduğunu söyleyebiliriz. Taekwondo yapılan spor merkezleri ve kulüplerinde fair play prensipleri olduğu belirlenmiştir. 


\section{KAYNAKLAR}

Arıpınar, E., Donuk, B. (2011). Fair Play. Ötüken Yayınevi. s.29.İstanbul.

Donuk, B., Şenduran F.S. (2006). Futbolun Anatomisi. Ötüken Yayınları. S.57- 65.İstanbul.

Erkal, M. E., Güven, Ö., Ayan, D. (1998). Sosyolojik Açıdan Spor. Der Yayınları.

Ghorbanzadehkoshki, B. (2009). Milli Olan ve Olmayan Tekwandocuların Bazı Fiziksel Özelliklerinin İncelenmesi. Ankara Üniversitesi Sağlı Bilimleri Enstitüsü, Yayımlanmamış Yüksek Lisans Tezi, Ankara.

Gündoğdu, C., Bingöl, H., Mutlutürk, N., Türkmen, M. (2010). Üniversitelerde Öğrenim Gören Taekwondo Milli Takım Sporcularının Sosyo Ekonomik Durumları ile Bu Branşa Katılım Nedenlerinin Araştırılması. Celal Bayar Üniversitesi Beden Eğitimi ve Spor Bilimleri Dergisi (BESBD), 5(3), 119-125.

Hausmann, M. (1998). Taekwondo (TKD). Hochladen Und Kostenlos Publizieren.

Hergüner, G., Tel, M. (2019). Fair Play İle Değerler Bağlamında Beden Eğitimi ve Spor. Her Yönüyle Spor, 575-594.

http://www.gsgm.gov.tr/sayfalar/ istatistik/sporcusayilari.htm) Erişim Tarihi: 10.06.2010

Karasar, N. (2006). Bilimsel Araştırma Yöntemi. Nobel Yayınları. S.77. Ankara.

Kim C.K, (1975). Taekwondo. s:11-13, Ankara.

Kim, S.K. What is Taekwondo (The Concept of Taekwondo), WTF, Taekwondo, 2006: No. 55(1), 27-28.

Kutlu, M., Tel, M., Ağaoğlu, S.A., Onay, M., Aydos, L., (1996). Türk Tekvando Millî Takım Düzeyi Sporcularının Fiziksel ve Fizyolojik Profilleri, H.Ü. IV. Spor Bilimleri Kongresi Bildiri Özetleri, 1-3 Kasım

Özsoy, O., Ş., Eler, S., Eler, N. (2018). Elit Taekwondo ve Poomse Oyuncularının Fiziksel ve Fizyolojik Parametrelerinin İncelenmesi. Atatürk Üniversitesi Beden Eğitimi ve Spor Bilimleri Dergisi, 20(1), 46-53.

Pehlivan, Z. (2004). Fair-Play Kavramının Geliştirilmesinde Okul Sporunun Yeri ve Önemi. Spormetre Beden Eğitimi ve Spor Bilimleri Dergisi. I1 (2), 49-53.

Pehlivan, Z., \& Konukman, F. (2004). Fair-Play Kavramının Geliştirilmesinde Okul Sporunun Yeri ve Önemi. Spormetre Beden Eğitimi ve Spor Bilimleri Dergisi, 2(2), 49-53.

Pehlivan, Z., (1992). Üniversiteye Yeni Kayıt Yaptıran Öğrencilerin Spor Eğilimi Üzerine Bir Araştırma (Fırat Üniversitesi Örneği), Spor Bilimleri 2. Ulusal Kongresi Bildirileri, Spor Bilimleri ve Teknolojisi Yüksek Okulu Yayını, Y.No:3, S:99-104.

Şahan, H. (2008). Üniversite Öğrencilerinin Sosyalleşme Sürecinde Spor Aktivitelerinin Rolü. Karamanoğlu Mehmetbey Üniversitesi Sosyal ve Ekonomik Araştırmalar Dergisi, (2), 248-266. 
Şahin, M. (2002). Taekwondocuların, Taekwondo Sporuna Algılamalarına Yönelik Tutumlarını Çeşitli Değişkenlere Göre Karşılaştırılması. GSGM Yayını, 19-20.

Tel M. (2008). Bir Spor Dalı Olarak Taekwondo. e-Journal of New World Sciences Academy, $\mathrm{V}: 3, \mathrm{~N}: 4$.

Tel, M, Arslan C., Ramazanoğlu F. (2004). Elit Düzey Taekwondocularda Görülen Spor Sakatlıkları ve Nedenleri, Sendrom IV, Spor Ve Tıp Dergisi, C:12, S:6, 21-24, Aralık.

Tel, M., (2006). Türk Taekwondo Milli Takım Sporcularının Seçilen Bazı Fiziksel ve Fizyolojik Özelliklerinin Analizi. Yüksek Lisans Tezi, Fırat Üniversitesi. Sağlik Bilimler Enstitüsü. Elazı̆̆

Tel, M., Öcalan, M., Yaman, M. (2001).Taekwondocuların bu sporu tercih etme nedenleri ve sosyo ekonomik durumları, Türkiye Sosyal Araştırmalar Dergisi, 3 (1), 3-5.

Toh, H.Y.K., (1980). Taekwondo Art. Science and a Sport. World Taekwondo Consolidated Edition, Winter-Spring, No:9.

Türkmen, M., (2004). Uzakdoğu Sporlarının (UDS) Çocuk Gelişimine Etkisi. Sakarya Üniversitesi Eğitim Fakültesi Dergisi, 8, 562-582.

Yalçınkaya, G.Z. (1986). Teakwondo. Hilal Matbaacılık. İstanbul. p.21-22.

Yıldırım, A., Şimşek, N. (2005). Sosyal Bilimlerde Nitel Araştırma Yöntemleri. Seçkin Yayınc1lik, Ankara.

Yıldız, H. (2016). Spor Yöneticilerinin Etik Davranışları (Doctoral dissertation, Selçuk Üniversitesi Sağlık Bilimleri Enstitüsü, Spor Yöneticiliği Anabilim Dalı, Konya. 